\title{
Improving HbA1c Control in Type 1 or Type 2 Diabetes Using Flash Glucose Monitoring: A Retrospective Observational Analysis in Two German Centres
}

Ludger Rose · Gerhard Klausmann · Alexander Seibold

Received: September 18, 2020 / Accepted: November 24, 2020 / Published online: December 11, 2020

(C) The Author(s) 2020

\section{ABSTRACT}

Introduction: The aim of this study was to evaluate change in laboratory-measured HbA1c in patients with either type 1 diabetes (T1D) or type 2 diabetes (T2D) on insulin therapy following initiation of the FreeStyle Libre ${ }^{\mathrm{TM}}$ flash glucose monitoring system.

Methods: This was a retrospective observational study on adults with T1D or T2D on insulin, who were started on the FreeStyle Libre system as part of standard care. HbA1c was recorded at initiation and at 3-month intervals thereafter.

Results: The analysis included 131 patients with T1D and 176 patients with T2D on insulin. Mean HbA1c decreased significantly by 3 months following initiation of the FreeStyle Libre system, both in T1D $(-0.75 \%, p<0.001)$ and in $\mathrm{T} 2 \mathrm{D}(-0.54 \%, p<0.001)$. Reductions were maintained for 12 months. Change from 3 to 12 months was not significant either in T1D

L. Rose

Zentrum für Diabetes und Gefäßerkrankungen

Münster, Munster, Germany

G. Klausmann

Gemeinschaftspraxis Drs. Klausmann,

Aschaffenburg, Germany

A. Seibold $(\bowtie)$

Abbott Diabetes Care, Wiesbaden, Germany

e-mail: alexander.seibold@abbott.com or T2D. Subgroup analysis showed significant reduction in patients with a baseline HbA1c $>7.5-10 \%$, both in T1D $(-0.59 \%$, $p<0.001)$ and in T2D on insulin $(-0.62 \%$, $p<0.005)$ at 12 months. Reductions for subjects with $\mathrm{HbA} 1 \mathrm{c}>10 \%$ were $-4.66 \%$ in $\mathrm{T} 1 \mathrm{D}$ and $-3.73 \%$ in $\mathrm{T} 2 \mathrm{D}$. No change was seen for subjects with a baseline HbA1c $\leq 7.5 \%$ (58 $\mathrm{mmol} / \mathrm{mol})$. Linear regression confirms that baseline HbA1c is strongly negatively correlated with subsequent change in HbA1c in T1D and in T2D.

Conclusions: Patients with T1D or T2D show a reduction in HbA1c by 3 months following initiation of the FreeStyle Libre system. The mean fall in HbA1c at 3 months is strongly negatively correlated with starting HbA1c. This reduction is maintained over 12 months. The significant benefit is seen in patients with a starting $\mathrm{HbA} 1 \mathrm{c}>7.5 \%(58 \mathrm{mmol} / \mathrm{mol})$.

Keywords: Flash glucose monitoring; FreeStyle libre; Glycemic control; HbA1c; Type 1 diabetes; Type 2 diabetes 


\section{Key Summary Points}

Why carry out this study?

To evaluate change in HbA1c over 12 months in people with either type 1 diabetes or type 2 diabetes on insulin in real-world care in Germany following initiation of the FreeStyle Libre ${ }^{\mathrm{TM}}$ flash glucose monitoring system.

To evaluate the correlation between change in HbA1c over 12 months following initiation of the FreeStyle Libre $^{\mathrm{TM}}$ system with $\mathrm{HbA1c}$ at baseline.

To evaluate the relationship between change in HbA1c with prior metabolic control following initiation of the FreeStyle Libre ${ }^{\mathrm{TM}}$ system.

\section{What was learned from the study?}

In real-world diabetes care in Germany, $\mathrm{HbA1c}$ is significantly reduced in people with T1D $(-0.75 \%)$ or T2D $(-0.54 \%)$ on insulin after initiation of the FreeStyle Libre $^{\mathrm{TM}}$ system ( $p<0.001$ in both cases).

The reduction in $\mathrm{HbA1c}$ is achieved within 3 months of initiation and is sustained over 12 months.

The most significant benefit is seen in patients with poorer metabolic control, with baseline HbA1c levels > 7.5\% (58 $\mathrm{mmol} / \mathrm{mol}$ ) prior to initiation of the FreeStyle Libre ${ }^{\mathrm{TM}}$ system.

Baseline HbA1c is negatively correlated with subsequent change in HbA1c with the FreeStyle Libre ${ }^{\mathrm{TM}}$ system. In T1D mean $\mathrm{HbA} 1 \mathrm{c}$ falls by $0.72 \%$ for each $1 \%$ increase in baseline HbA1c. In T2D on insulin, mean $\mathrm{HbA} 1 \mathrm{c}$ falls by $0.71 \%$ for each $1 \%$ increase in baseline HbA1c.

\section{DIGITAL FEATURES}

This article is published with digital features, including a summary slide, to facilitate understanding of the article. To view digital features for this article go to https://doi.org/10.6084/ m9.figshare.13281419.

\section{INTRODUCTION}

HbA1c is the established gold-standard indicator for assessing long-term glucose control in diabetes. Landmark clinical trials, including the UK Prospective Diabetes Study (UKPDS) [1] and the Diabetes Control and Complications Trial (DCCT) [2], have established that a lower HbA1c is associated with clinically significant reductions in the incidence of microvascular complications and long-term macrovascular disease. Real-time continuous glucose monitoring (rtCGM) devices have been shown to help patients with type 1 diabetes (T1D) or type 2 diabetes (T2D) on insulin therapy to reduce HbA1c levels [3]. As well as reducing laboratorymeasured HbA1c levels, randomised clinical trials (RCTs) indicate that there is also a reduction in episodes of hypoglycaemia and glycaemic variability with rtCGM devices, in comparison to self-monitored blood glucose (SMBG) testing [4-8].

The FreeStyle Libre ${ }^{\mathrm{TM}}$ system (Abbott Diabetes Care, Witney, UK) is a factory-calibrated interstitial glucose monitoring system in which a sensor is applied to the upper arm and collects glucose readings over a 14-day wear period [9]. The sensor automatically measures glucose every minute and readings are stored in 15-min intervals. Glucose readings are not automatically communicated to the FreeStyle Libre reader, rather the data is collected when the user scans the sensor either with the reader or a smartphone app [10]. This type of CGM is also known as intermittently scanned CGM (isCGM) or flash glucose monitoring. Two RCTs of the FreeStyle Libre system in T1D and T2D on insulin have shown significant reductions in time in hypoglycaemia without demonstrating a significant change in HbA1c levels [11, 12]. In contrast, recent prospective studies have shown 
improvements in $\mathrm{HbA} 1 \mathrm{c}$ for children and adults using the FreeStyle Libre system in T1D and for adults with T2D on insulin [13-18].

Here we report on the experience of two treatment centres in Germany, where the FreeStyle Libre system was introduced to patients with either T1D or T2D on insulin as part of standard care, and $\mathrm{HbA} 1 \mathrm{c}$ values recorded over 12 months following initiation.

\section{METHODS}

\section{Study Selection Criteria and Outcomes Measure}

This retrospective observational analysis was performed on data collected at two German clinical centres, the Gemeinschaftspraxis Drs. Klausmann in Aschaffenburg and Zentrum für Diabetes und Gefäßerkrankungen Münster. Both centres are established in delivering standard outpatient care for people with diabetes within the German healthcare system. Deidentified patient records were examined to select subjects with either T1D or T2D on insulin who were initiated on the FreeStyle Libre system as part of standard care. No selection criteria were applied other than treatment with FreeStyle Libre as part of standard care. The data reflect consecutive adult patients started on FreeStyle Libre between November 2015 and September 2018. No FreeStyle Libre sensorderived glucose data is reported in this study. Laboratory tested $\mathrm{HbA1c}$ values were recorded for all patients prior to the start of FreeStyle Libre using standard clinical laboratory reference analyzers, with at least one HbA1c value that was established after starting. Not all subjects had data recorded at each interval across the 12-month analysis period, as a consequence of the time of their start of FreeStyle Libre or a missed attendance.

\section{Statistics}

Matched paired data were analysed using both the data analysis tools in Microsoft Excel 2016 and the $\mathrm{R}$ Project for Statistical Computing (www.r-project.org) software version 3.6.2. The level of significance was set at 0.05 or better. A linear model was used to investigate the trend of mean $\mathrm{HbA1c}$ values across the measurement time points from baseline onwards. Student's $t$ test was used to compare means of matched paired data and unmatched data as appropriate to the analysis. Tukey's contrast analysis was used to compare the means of every outcome time point from 3 months onwards. Linear regression was used to identify the predicted change in $\mathrm{HbA1c}$ given the input baseline HbA1c.

\section{Compliance with Ethics Guidelines}

This retrospective observational study used only existing de-identified electronic medical record data that were collected in daily clinical practice. No intervention was implemented on the subjects for the purpose of the study, and no patient-identifiable information was used in the study. The study was compliant with the Helsinki Declaration of 1964, and its later amendments.

\section{RESULTS}

\section{Inclusion Criteria and Baseline Characteristics}

A total of 131 patients with T1D and 176 patients with T2D on insulin met the inclusion criteria and were included in the analysis. The age of patient ranged from 24 to 92 years. All patients were recorded as being on insulin therapy for the duration of the analysis, either on multiple daily doses of insulin (MDI), mealtime insulin only or continuous subcutaneous insulin infusion (CSII). The baseline characteristics of the study population are provided in Table 1.

\section{Change in Laboratory Measured HbA1c}

A statistically significant reduction in mean HbA1c from baseline was detected at all time points in 131 patients with T1D (Fig. 1). Mean 
Table 1 Baseline characteristics of the study populations in T1D and T2D

\begin{tabular}{lll}
\hline & Type $\mathbf{1}$ diabetes $(\boldsymbol{n}=\mathbf{1 3 1})$ & Type 2 diabetes $(\boldsymbol{n}=\mathbf{1 7 6})$ \\
\hline Age (years) & $42.37 \pm 16.81[11,81]$ & $62.82 \pm 11.31[34,92]$ \\
Duration of diabetes & $16.34 \pm 13.31[1,60]$ & $14.20 \pm 8.55[1,52]$ \\
HbA1c $\% \pm$ SE) & $8.15 \pm 0.15$ & $7.76 \pm 0.12$ \\
Insulin therapy (\% of patients) & & $0 \%$ \\
CSII & $12.2 \%$ & $100 \%$ \\
MDI* & $87.8 \%$ & \\
\hline
\end{tabular}

Age and duration of diabetes are presented as the mean \pm standard deviation (SD) with the range in square brackets $S E$ standard error of the mean, CSII continuous subcutaneous insulin infusion, $M D I$ multiple daily injections with insulin, $T 1 D$ type 1 diabetes, $T 2 D$ type 2 diabetes

*Patients on a variety of injection therapies, including mealtime only and basal bolus insulin therapy

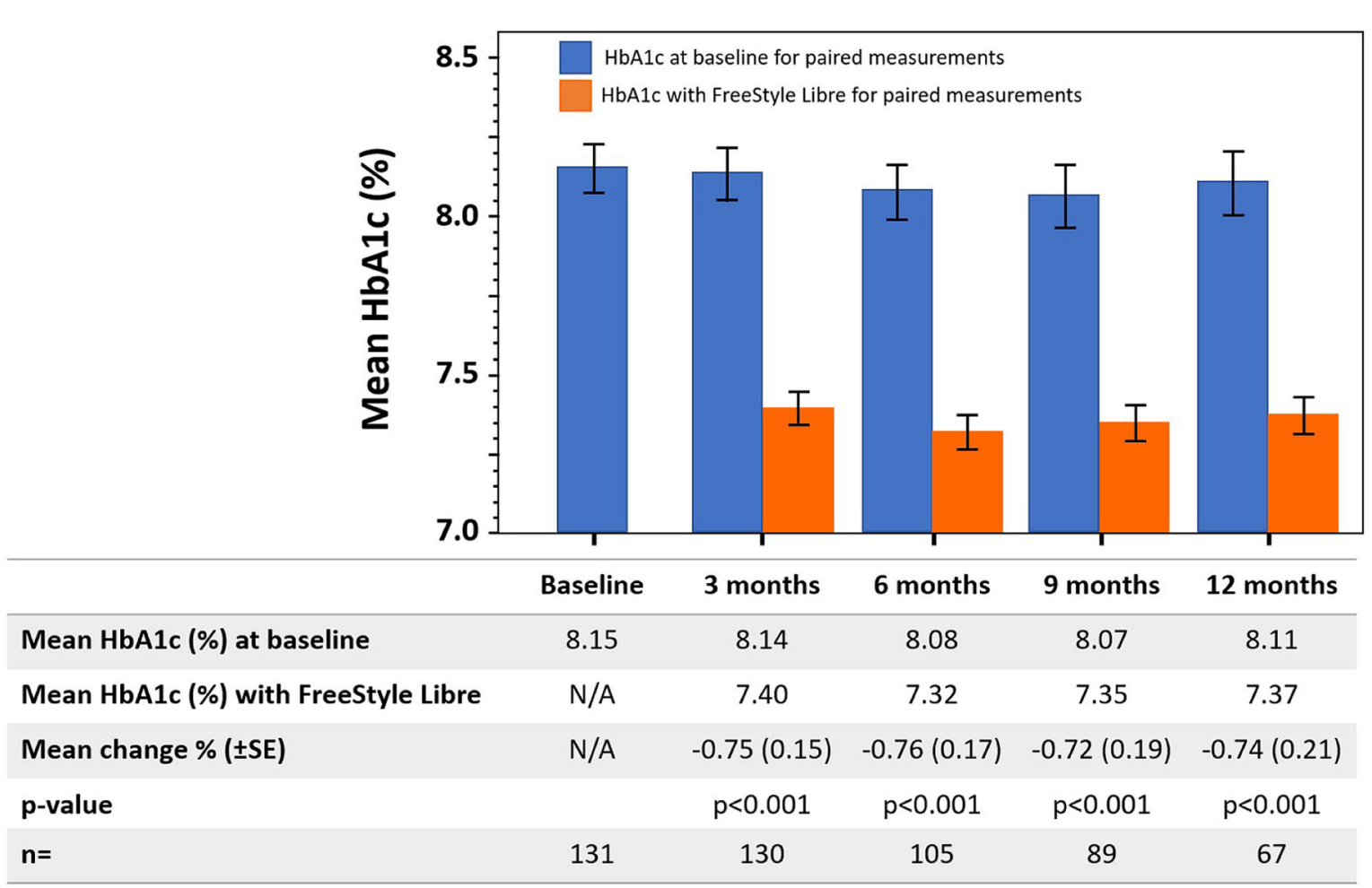

Fig. 1 Mean HbAlc levels for 131 patients with type 1 diabetes at 3-monthly intervals, following initiation of the FreeStyle Libre flash glucose monitoring system. Each time point contains the data for the cohort of study subjects with both a baseline and an intervention $\mathrm{HbAlc}$ reading for that time point. All subjects $(n=131)$ had a baseline $\mathrm{HbAlc}$, but not all subjects provided HbAlc data for all time points thereafter. The data shown in the table is the mean baseline and $\mathrm{HbAlc}$ at each time point, and the mean change in HbAlc. Data are shown as mean HbAlc (\%) \pm standard error (SE). Patients experienced a statistically significant reduction in HbAlc levels from baseline, which was sustained over 12 months. Differences in mean HbAlc were not significant between 3 and 12 months 


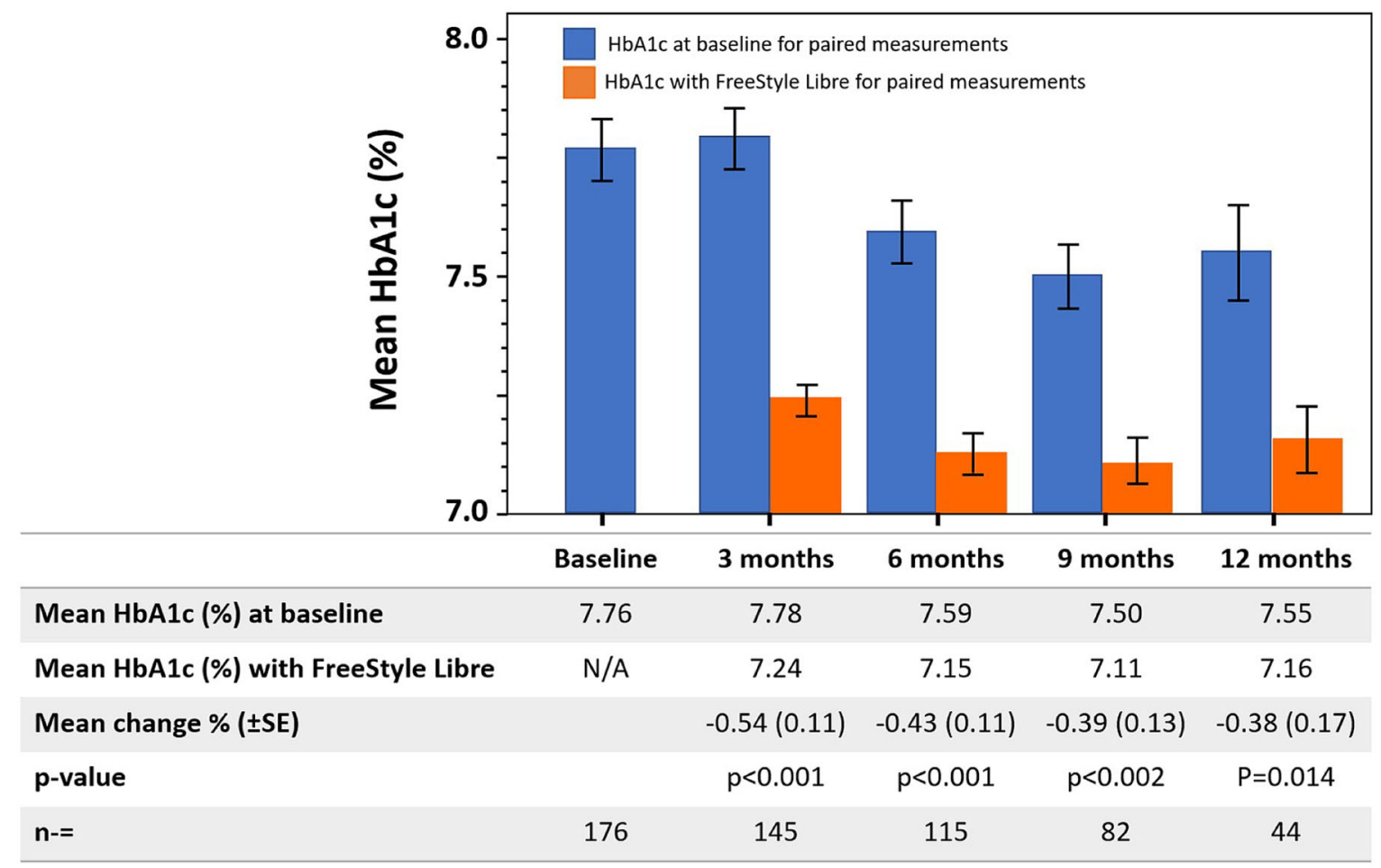

Fig. 2 Mean HbAlc levels for 176 patients with type 2 diabetes at 3-monthly intervals, following initiation of the FreeStyle Libre flash glucose monitoring system. Each time point contains the data for the cohort of study subjects with both a baseline and an intervention HbAlc reading for that time point. All subjects $(n=176)$ had a baseline $\mathrm{HbAlc}$, but not all subjects provided HbAlc data for all

starting baseline $( \pm$ SE) was $8.15 \%( \pm 0.15 \%)$. HbA1c values decreased by $-0.75 \%( \pm 0.15 \%)$ at 3 months, by $-0.76 \% \quad( \pm 0.17 \%)$ at 6 months, by $-0.72 \%( \pm 0.19 \%)$ at 9 months and by $0.74 \% \quad( \pm 0.21 \%)$ at 12 months $(p<0.001$ in all cases; Fig. 1$)$. A similar trend was seen in 176 patients with T2D on insulin (Fig. 2), with a mean baseline HbA1c of $7.76 \%$ $( \pm 0.12 \%)$. HbA1c was reduced by $-0.54 \%$ $( \pm 0.11 \%)$ at 3 months, by $0.43 \%( \pm 0.11 \%)$ at 6 months, by $-0.39 \%( \pm 0.13 \%)$ at 9 months and by $-0.38 \%( \pm 0.17 \%)$ at 12 months $(P<0.001$ at 3 and 6 months, $P<0.002$ at 9 months; $P=0.014$ at 12 months; Fig. 2).

Tukey contrast analysis both in T1D and T2D showed that the difference between time points after 3 months was not significant, indicating that the greatest impact on HbA1c values was time points thereafter. The data shown in the table is the mean baseline and HbAlc at each time point, and the mean change in HbAlc. Data are shown as mean HbAlc (\%) \pm standard error (SE). Patients experienced a statistically significant reduction in $\mathrm{HbAlc}$ levels from baseline, which was sustained over 12 months. Differences in mean HbAlc were not significant between 3 and 12 months

observed within the first 3 months of use of the FreeStyle Libre system and sustained for 12 months.

\section{Change in HbA1c in Patients Stratified by Baseline Metabolic Control}

In a subgroup analysis centred on metabolic control, we stratified patients into those with baseline $\mathrm{HbA} 1 \mathrm{c} \leq 7.5 \%(58 \mathrm{mmol} / \mathrm{mol})$, those with baseline HbA1c $>7.5-10 \%$ (> 58-$86 \mathrm{mmol} / \mathrm{mol}$ ) and those with $\mathrm{HbA1c}>10 \%$ (>86 mmol/mol). This showed that patients with T1D or T2D on insulin and with a baseline HbA1c $>7.5 \%$ (> $58 \mathrm{mmol} / \mathrm{mol})$ achieved a significant reduction in HbA1c over time with FreeStyle Libre, whereas those with HbA1c 


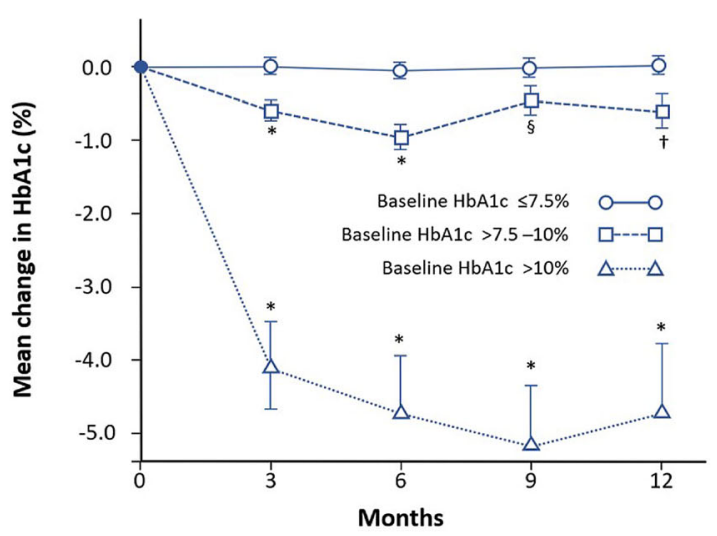

Fig. 3 Mean change in HbAlc over 12 months for patients with baseline HbAlc $\leq 7.5 \%$, HbAlc $>7.5-10 \%$ and HbAlc $>10 \% .{ }^{*} p<0.001$ for difference in mean change in HbAlc. ${ }^{\dagger} p<0.01$ for difference in mean change in HbAlc from baseline. $s_{p}=0.012$ for difference in mean change in $\mathrm{HbAlc}$ from

levels $\leq 7.5 \%$ (58 mmol/mol; Fig. 3a, b) did not. For all patients with $\mathrm{HbA1c}$ in the range $>7.5-10 \% \quad(>58-86 \mathrm{mmol} / \mathrm{mol}) \quad$ the change at 12 months was significant but was considerably greater amongst patients with HbA1c $>10 \%(86 \mathrm{mmol} / \mathrm{mol})$. For people with T1D, those with mean HbA1c $>7.5-10 \%$ (> 58-86 mmol $/ \mathrm{mol}$ ) achieved a clinically significant reduction of $0.59 \%( \pm 0.19 \%)$ after 12 months, from a mean HbA1c from $8.49 \%$ to $7.90 \%$ (Fig. 3a; $p<0.01$ ). For those with a baseline $\mathrm{HbA} 1 \mathrm{c}>10 \%(86 \mathrm{mmol} / \mathrm{mol})$ there was a mean $4.66 \%( \pm 0.87 \%)$ reduction, from $11.83 \%$ to $7.17 \%$ (Fig. $3 \mathrm{a} ; p<0.001$ ). In people with T2D on insulin and HbA1c $>7.5-10 \%$ ( $>58-86 \mathrm{mmol} / \mathrm{mol}$ ), the reduction in mean HbA1c 12 months after starting FreeStyle Libre was $0.62 \%( \pm 0.22 \%)$, from 8.43 to $7.81 \%$ (Fig. 3b; $p<0.01$ ) and for patients with $\mathrm{HbA} 1 \mathrm{c}>10 \%(86 \mathrm{mmol} / \mathrm{mol})$ the reduction at 12 months was $3.73 \%$ (from $11.4 \%$ to $7.67 \%$; $p<0.01)$.

\section{Relationship Between Baseline HbA1c and Change in HbA1c at 3 months After Starting FreeStyle Libre}

Linear regression was used to identify the predicted change in $\mathrm{HbA1c}$ at 3 months, given the

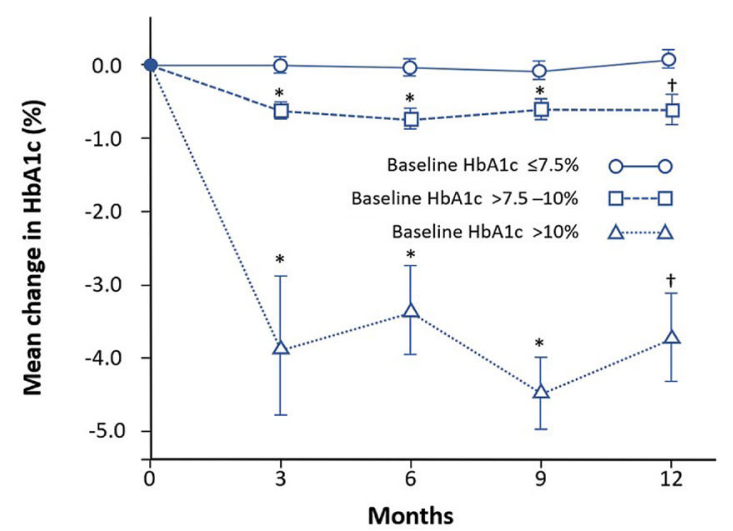

baseline. Data are shown as mean change in HbAlc (\%) \pm standard error (SE). A significant decrease in HbAlc is observed in patients with a baseline HbAlc $>$ $7.5 \%(58 \mathrm{mmol} / \mathrm{mol})$ for all time points $(p<0.001)$, whereas those with a baseline HbAlc $\leq 7.5 \%$ $(58 \mathrm{mmol} / \mathrm{mol})$ did not demonstrate a significant decrease

input baseline $\mathrm{HbA1c}$. This confirms that baseline $\mathrm{HbA1c}$ is strongly negatively correlated with subsequent change in HbA1c, both in T1D $\left(R^{2}=0.602, p<0.001 ;\right.$ Fig. $\left.4 \mathrm{a}\right)$ and in T2D $\left(R^{2}=0.698, p<0.001 ;\right.$ Fig. $\left.4 \mathrm{~b}\right)$. In T1D, on average, for each percentage increase in mean initial HbA1c, the mean change in final HbA1c at 3 months falls by an additional $0.72 \%(95 \%$ CI -0.83 to -0.62 ). In T2D, for each percentage increase in mean initial $\mathrm{HbA1c}$, the mean change in final HbA1c falls by an additional $0.71 \%$ (95\% CI -0.79 to -0.64$)$. No correlation was seen between change in HbA1c and age at diagnosis, age at intervention or duration of diabetes (data not shown).

\section{DISCUSSION}

Our retrospective observational analysis of diabetes management in a real-world setting shows that there is a significant and rapid reduction in HbA1c in patients with either T1D or T2D on insulin following the introduction of the FreeStyle Libre system to their standard care. These outcomes differ from two RCTs previously undertaken to evaluate the impact of the FreeStyle Libre system. In both the IMPACT [11] study in patients with T1D and the REPLACE [12] study in patients with T2D on insulin, no 

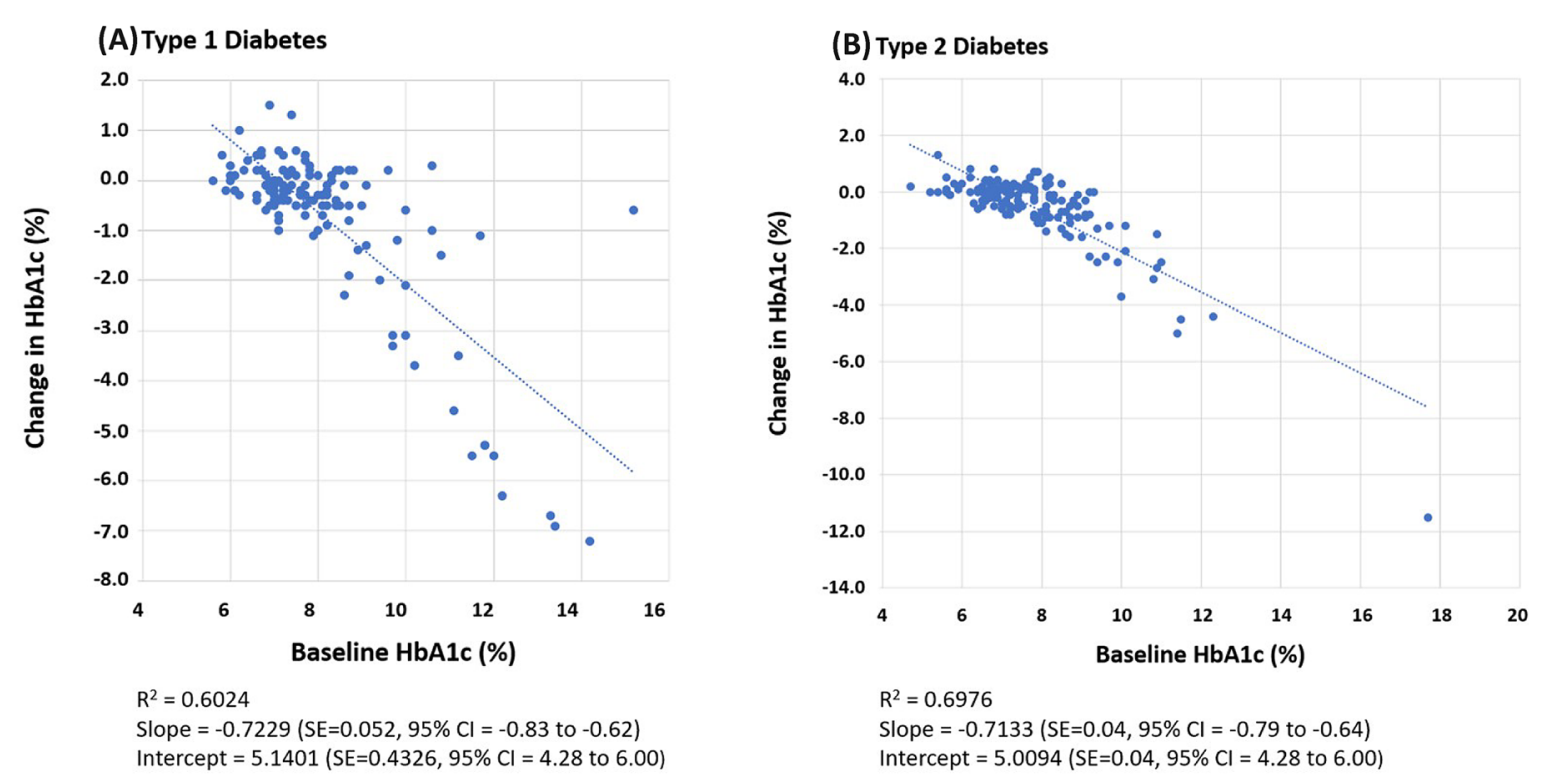

Fig. 4 Relationship between baseline HbAlc and change in HbAlc at 3 months following initiation of FreeStyle Libre. Linear regression was performed on paired baseline and 3-month laboratory-measured HbAlc data

significant change was demonstrated in HbA1c levels over 26 weeks when the FreeStyle Libre system was compared with SMBG. In IMPACT, the study population was well controlled, with a baseline mean $\mathrm{HbA} 1 \mathrm{c}<7.5 \%(58 \mathrm{mmol} / \mathrm{mol})$, whereas in REPLACE the baseline mean HbA1c was $>8.5 \%(64 \mathrm{mmol} / \mathrm{mol})$. Only in a prespecified subgroup analysis of patients under 65 years in the REPLACE study was a significant change in HbA1c seen compared with SMBG controls $(-0.33 \% ; p=0.0301)$ [12]. In contrast, the single-arm SELFY study [13] in a paediatric population with T1D demonstrated a significant reduction in $\mathrm{HbA1c}(-0.4 \%, p<0.001)$ when using the FreeStyle Libre system compared to SMBG over 8 weeks. Recent prospective data from 107 adult subjects with T1D in Belgium [16] demonstrated a reduction in HbA1c of $-0.74 \%$ after 3 months following introduction of the FreeStyle Libre system. A larger prospective study on adults with T1D in Scotland [15] has demonstrated that $48.1 \%$ of 750 subjects achieved a reduction in $\mathrm{HbA} 1 \mathrm{c}$ of $0.5 \%$ or more over a median 245 days (8 months) following introduction of the FreeStyle Libre system. In $\mathrm{T} 2 \mathrm{D}$, a prospective study in two centres in Israel on 101 adults with T2D on insulin demonstrated a $-0.49 \%$ reduction in
HbA1c from baseline over 10 weeks compared to subjects assigned to the intervention arm using the FreeStyle Libre system $(p=0.005)$ [14] and a recent retrospective chart-review study across 18 European diabetes centres showed a reduction of $-0.9 \%$ in $\mathrm{HbA} 1 \mathrm{c}$ for people with T2D managed by basal-bolus insulin 3-6 months after starting the FreeStyle Libre system [18].

The outcomes from two German diabetes treatment centres reported here confirm these improvements in $\mathrm{HbA} 1 \mathrm{c}$ for patients with either T1D or T2D on insulin. The reductions in HbA1c occur within the first 3 months and are sustained over a 12-month period. Linear regression shows that the major predictor of a reduction in $\mathrm{HbA1c}$ after starting the FreeStyle Libre system is HbA1c at baseline. For each percentage increase in mean initial $\mathrm{HbA1c}$, the mean change in final HbA1c at 3 months in T1D falls by an additional $0.72 \%$, and by $0.71 \%$ in T2D on insulin. The subgroup analysis of subjects based on prior metabolic control (Fig. 3) showed that a clinically significant reduction in HbA1c from baseline is achievable for people with T1D or T2D on insulin with mean HbA1c $>7.5-10 \%$ (> 58-86 mmol $/ \mathrm{mol})$ after starting the FreeStyle Libre system, with 
greater reductions for patients with $\mathrm{HbA1c}$ above $10 \%$ (> $86 \mathrm{mmol} / \mathrm{mol}$ ). People with T1D or T2D on insulin and good prior glucose control (mean $\mathrm{HbA} 1 \mathrm{c} \leq 7.5 \%$ at baseline) do not see a significant change in their HbA1c over 3-12 months.

Despite the lack of change in HbA1c, those patients with tighter long-term glucose control, as evidenced by a starting HbA1c level below $7.5 \%$, are likely to be improving their metabolic control using the FreeStyle Libre system, but not by reducing the HbA1c. The outcomes from the IMPACT trial [11] for patients with T1D and in the REPLACE trial [12] for subjects with T2D on MDI indicate that all patients using FreeStyle Libre can expect to significantly reduce both their time in hypoglycaemia below $70 \mathrm{mg} / \mathrm{dL}$ $(3.9 \mathrm{mmol} / \mathrm{L})$ and below $54 \mathrm{mg} / \mathrm{dL}(3.0 \mathrm{mmol} /$ $\mathrm{L})$, as well as reducing their frequency of lowglucose events. This level of analysis in the current study would require inclusion of sensordependent glucose data which is not possible in the setting of this retrospective observational study.

The observation that change in HbA1c happens within the first 3 months is not surprising. Many studies have shown that reductions in a range of glycemic measures, including HbA1c, rapidly follow the introduction both of rtCGM or the FreeStyle Libre system as part of diabetes care. A recent meta-analysis of 29 RCTs or realworld studies in children and adults with T1D or T2D showed that the significant reductions in HbA1c following initiation of the FreeStyle Libre system were seen between 2 and 4 months after starting [17]. This is postulated to be a consequence of the immediate access for users of the FreeStyle Libre system to a range of glycemic information that can improve their decision-making during daily diabetes self-care. These include their glucose status in real time, the trend arrows that indicate the direction and speed of change in their glucose status [19] and the summary reports that are available to them via the readers or smartphone apps that they use to scan and collect glucose data. This information facilitates an in-depth awareness of their daily life and allows for effective treatment decisions that are not possible with SMBG testing. The intuitive nature of CGM systems mean that this improvement in self-care behaviour starts following the application of the first glucose sensor and is sufficient for a change in long-term HbA1c to be evident after 3 months.

It is important to acknowledge that our realworld study has limitations. It is a retrospective chart-review study in which limited additional demographic information is available or presented other than age, diabetes status and duration, and insulin regime. In this context, it must be acknowledged that initiating use of the FreeStyle Libre system is only one of a number of factors that may have had an impact on the observed outcomes. For example, training on the FreeStyle Libre device along with specific diabetes education from their healthcare professionals during the initiation process can result in improved diabetes self-care behaviours independent of the device itself that are not controlled for in this retrospective observational analysis. However, our interpretation is that the benefits of immediate and longer-term awareness of glucose trends and patterns, provided by the FreeStyle Libre system, are empowering many of the users to make betterinformed and proactive decisions about daily glucose control, both in terms of their diet and lifestyle, as well as improved management of their insulin therapy. This particularly applies to the subset of patients with poorer glucose control at the point at which the FreeStyle Libre system has been initiated. The strengths of our study are the unrestricted inclusion criteria, the significant number of people with type 2 diabetes on insulin and the use of a single, consistent outcome.

Ultimately, the data reported here adds to the growing real-world evidence highlighting the impact of flash glucose monitoring on glycaemic control for people with T1D or T2D. Importantly, it confirms that people with T2D on insulin therapy see a considerable benefit in long-term HbA1c when managed with flash glucose monitoring. This is in agreement with the outcomes of a much shorter 10-week prospective interventional study on 101 patients with T2D on insulin [14] and also concur with the outcomes of a real-world observational study over 3-6 months, which included 183 adults with T2D managed with 
basal-bolus insulin from German diabetes centres [18]. Our retrospective observational analysis has demonstrated similar results within a population of patients with T2D on insulin in Germany, over an extended 12-month period. The data presented here is also aligned with previous real-world studies in T1D showing that the greatest reduction in $\mathrm{HbA1c}$ is attained by subjects with a higher baseline [14-17].

\section{CONCLUSIONS}

The results presented here build on the evidence for improved glucose control, as measured by HbA1c, using flash glucose monitoring in patients with either T1D or T2D on insulin. This retrospective observational analysis shows that the introduction of the FreeStyle Libre system is associated with a significant reduction in $\mathrm{HbA1c}$ levels in people with diabetes on insulin within 3 months of initiation and the results are sustainable over 12 months. Furthermore, the most significant benefit regarding HbA1c reduction is seen in patients whose baseline HbA1c levels are above $7.5 \%$ $(58 \mathrm{mmol} / \mathrm{mol})$. These improvements in glucose control may contribute to a reduction in the long-term risk of microvascular and macrovascular complications and the consequent costs of morbidity and mortality associated with diabetes.

\section{ACKNOWLEDGEMENTS}

Funding. Funding for this analysis and the journal's Rapid Service Fee were provided by Abbott Diabetes Care.

Medical Writing, Editorial and Other Assistance. Medical writing and editorial assistance in the preparation of this article was provided by Dr Robert Brines of Bite Medical Consulting. Support for this assistance was funded by Abbott Diabetes Care.

Authorship. All named authors meet the International Committee of Medical Journal
Editors (ICMJE) criteria for authorship for this article, take responsibility for the integrity of the work as a whole, and have given their approval for this version to be published.

Disclosures. Ludger Rose has participated in advisory panels for Novo Nordisk and acted as a consultant for and is a member of the Association of Statutory Health Insurance Physicians. Gerhard Klausmann has participated in advisory panels for Abbott Diabetes Care. Alexander Seibold is an employee of Abbott Diabetes Care.

Compliance with Ethics Guidelines. This retrospective observational study used only existing anonymized electronic medical record data that were collected in daily clinical practice. No intervention was implemented on the subjects for the purpose of the study, and no patient-identifiable information was used in the study. The study was compliant with the Helsinki Declaration of 1964, and its later amendments.

Data Availability. All data analyzed during this study are available from the corresponding author on reasonable request.

Open Access. This article is licensed under a Creative Commons Attribution-NonCommercial 4.0 International License, which permits any non-commercial use, sharing, adaptation, distribution and reproduction in any medium or format, as long as you give appropriate credit to the original author(s) and the source, provide a link to the Creative Commons licence, and indicate if changes were made. The images or other third party material in this article are included in the article's Creative Commons licence, unless indicated otherwise in a credit line to the material. If material is not included in the article's Creative Commons licence and your intended use is not permitted by statutory regulation or exceeds the permitted use, you will need to obtain permission directly from the copyright holder. To view a copy of this licence, visit http://creativecommons.org/licenses/by$\mathrm{nc} / 4.0 /$. 


\section{REFERENCES}

1. Holman RR, Paul SK, Bethel AM, Matthews DR, Neil AH. 10-year follow-up of intensive glucose control in type 2 diabetes. New Engl J Med. 2008;359(15): 1577-89. https://doi.org/10.1056/nejmoa0806470.

2. Nathan D, Genuth S, Lachin J. The effect of intensive treatment of diabetes on the development and progression of long-term complications in insulindependent diabetes mellitus. New Engl J Med. 1993;329(14):977-86. https://doi.org/10.1056/ nejm199309303291401.

3. Ajjan RA. How can we realize the clinical benefits of continuous glucose monitoring? Diabetes Technol Ther. 2017;19(S2):1-10. https://doi.org/10.1089/ dia.2017.0021.

4. Juvenile Diabetes Research Foundation Continuous Glucose Monitoring Study Group, Tamborlane WV, Beck RW, et al. Continuous glucose monitoring and intensive treatment of type 1 diabetes. New Engl J Med. 2008;359(14): 1464-1476. https://doi.org/10. 1056/nejmoa0805017.

5. Beck RW, Riddlesworth T, Ruedy K, et al. Effect of continuous glucose monitoring on glycemic control in adults with type 1 diabetes using insulin injections: the DIAMOND randomized clinical trial. JAMA. 2017a;317(4):371-8. https://doi.org/10. 1001/jama.2016.19975.

6. Beck RW, Riddlesworth TD, Ruedy K, et al. Continuous glucose monitoring versus usual care in patients with type 2 diabetes receiving multiple daily insulin injections. Ann Intern Med. 2017b;167(6): 365. https://doi.org/10.7326/m16-2855.

7. Lind M, Polonsky W, Hirsch IB, et al. Continuous glucose monitoring vs. conventional therapy for glycemic control in adults with type 1 diabetes treated with multiple daily insulin injections: the GOLD randomized clinical trial. JAMA. 2017;317(4): 379-87. https://doi.org/10.1001/jama.2016.19976.

8. Battelino T, Conget I, Olsen B, et al. The use and efficacy of continuous glucose monitoring in type 1 diabetes treated with insulin pump therapy: a randomised controlled trial. Diabetologia. 2012;55(12):3155-62. https://doi.org/10.1007/s00125-012-2708-9.

9. Bailey T, Bode BW, Christiansen MP, Klaff LJ, Alva $\mathrm{S}$. The performance and usability of a factory-calibrated flash glucose monitoring system. Diabetes Technol Ther. 2015;17(11):787-94. https://doi.org/ 10.1089/dia.2014.0378.

10. Blum A. Freestyle libre glucose monitoring system. Clin Diabetes. 2018;36(2):cd170130. https://doi. org/10.2337/cd17-0130.
11. Bolinder J, Antuna R, Geelhoed-Duijvestijn P, Kröger J, Weitgasser R. Novel glucose-sensing technology and hypoglycaemia in type 1 diabetes: a multicentre, non-masked, randomised controlled trial. Lancet. 2016;388(10057):2254-63. https://doi. org/10.1016/s0140-6736(16)31535-5.

12. Haak T, Hanaire H, Ajjan R, Hermanns N, Riveline JP, Rayman G. Flash glucose-sensing technology as a replacement for blood glucose monitoring for the management of insulin-treated type 2 diabetes: a multicenter. Open-label randomized controlled trial. Diabetes Ther. 2017;8(1):55-73. https://doi. org/10.1007/s13300-016-0223-6.

13. Campbell FM, Murphy NP, Stewart C, Biester T, Kordonouri O. Outcomes of using flash glucose monitoring technology by children and young people with type 1 diabetes in a single arm study. Pediatr Diabetes. 2018;19(7):1294-301. https://doi. org/10.1111/pedi.12735.

14. Yaron M, Roitman E, Aharon-Hananel G, et al. Effect of flash glucose monitoring technology on glycemic control and treatment satisfaction in patients with type 2 diabetes. Diabetes Care. 2019: dc180166. https://doi.org/10.2337/dc18-0166.

15. Tyndall V, Stimson RH, Zammitt NN, et al. Marked improvement in HbA1c following commencement of flash glucose monitoring in people with type 1 diabetes. Diabetologia. 2019;62(8):1349-56. https://doi.org/10.1007/s00125-019-4894-1.

16. Paris I, Henry C, Pirard F, Gérard A, Colin IM. The new FreeStyle libre flash glucose monitoring system improves the glycaemic control in a cohort of people with type 1 diabetes followed in real-life conditions over a period of one year. Endocrinol Diabetes Metab. 2018;1(3):e00023. https://doi.org/ 10.1002/edm2.23.

17. Evans M, Welsh Z, Ells S, Seibold A. The impact of flash glucose monitoring on glycaemic control as measured by HbA1c: a meta-analysis of clinical trials and real-world observational studies. Diabetes Ther. 2020;11:83-95. https://doi.org/10.1007/ s13300-019-00720-0.

18. Kröger J, Fasching P, Hanaire H. Three European retrospective real-world chart review studies to determine the effectiveness of flash glucose monitoring on HbA1c in adults with type 2 diabetes. Diabetes Ther. 2020;11(1):279-91. https://doi.org/ 10.1007/s13300-019-00741-9.

19. Ziegler R, von Sengbusch S, Kröger J, et al. Therapy adjustments based on trend arrows using continuous glucose monitoring systems. J Diabetes Sci Technol. 2019;13(4):763-73. https://doi.org/10. $1177 / 1932296818822539$. 